\title{
A vida em suspensão:
}

\author{
'Fale com ela' e os sentidos da morte
}

Rosamaria Carneiro(a)

\section{Prefácio}

Nesta oportunidade ${ }^{(b)}$, tenho por desafio refletir sobre os muitos sentidos da morte e/ou 'vida em suspensão' a partir de 'Fale com ela', de Pedro Almodóvar, diretor conhecido por versar sobre temas como: sexualidade, erotismo, corporalidade, parentesco e violência, entre outras searas que tangenciam nossas vidas. Não tenho alternativa, a não ser partir da perspectiva antropológica, já que esse é o meu lugar de fala e de leitura do mundo.

Para tanto, este artigo está organizado em três momentos: notas sobre o diretor e sobre 'Fale com ela'; uma singela historiografia da morte no ocidente; e, por fim, uma reflexão sobre as noções de 'boa morte' e de 'morte natural', a partir da tecnologia, e suas implicações no campo da saúde na atualidade.

\section{Prenúncio da cria e de seu criador}

Pedro Almodóvar nasceu em Calzeda de la Calatrava, na Espanha, em 1951. Aos oito anos, mudou-se para Cáceres e, aos vinte anos, para Madrid. $\mathrm{Na}$ capital, começou a desenvolver suas atividades artísticas. De início, concentrouse em produção teatral, em 'Los Goliardos', porém, já em 1974, dirigiu os seus primeiros curtas-metragens em Super-8, transformando-se em um dos pioneiros de 'la movida madrilena'.

Seu primeiro longa-metragem foi 'Pepi, Luci, Bom y otras chicas del montón' (1980), rodado, inicialmente, em $16 \mathrm{~mm}$ e, mais tarde, convertido para $35 \mathrm{~mm}$. Rapidamente, converteu-se em um 'cult'. Com 'Entre tinieblas y ¿Qué he hecho yo para merecer ésto?' (1984), abriram-se as portas do reconhecimento e dos mercados fora da Espanha. E assim, com 'Mujeres al borde de un ataque de nervios' (1988), consolidou seu sucesso, ao ganhar o prêmio de melhor filme estrangeiro do ano. Depois de anos de altos e baixos, foi agraciado com o Oscar de Melhor Filme Estrangeiro com 'Todo sobre mi Madre' (1999), e, pouco depois, estourou com o sucesso de bilheteria 'Hable con ella', que conquistou o prêmio de Melhor Roteiro Original. E por último, mais recentemente, brindou-nos com 'Volver' (2006) e, em seguida, com o instigante 'Pele que Habito' (2011), estória de um médico/monstro que reconstrói o sexo e o corpo do algoz de sua filha, já morta. 
Em 'Fale com ela', deparamo-nos com Begnino e Marco, o primeiro, enfermeiro e, o segundo, jornalista. Os dois estão envolvidos com mulheres em coma, Alicia e Lydia. O coma, enquanto um estado de rebaixamento da consciência, difere dos ditos 'estados vegetativos', nos quais persistem somente movimentos automáticos e involuntários. Discute-se que, no coma, existe a possibilidade de retorno à vida, enquanto do estado vegetativo seria improvável. Entretanto, tanto em um caso como no outro, experimentar-se-iam situações de 'vida em suspensão' ou de outras vidas, que podem vir a ser também tidas ou consideradas como experiências de morte.

Alicia é uma bailarina, que vivia em coma há quatro anos, depois de um acidente de carro. Lydia é uma toureira, que, depois de ter sido 'partida en dos' por um touro, tem uma parte significativa de seu cérebro danificada. Duas mulheres hospitalizadas, que nada parecem saber do que acontece ao seu redor, e dois homens que se tornam amigos no interior de um hospital.

Begnino havia passado a vida toda cuidando de sua mãe, também enferma, e nunca havia se relacionado sexualmente com nenhuma mulher ou homem. Marco, ao que parece, havia se separado e carregava traumas da antiga relação. Juntos, dialogam e desabafam sobre o estado dessas mulheres, mas com perspectivas bastante distintas. Enquanto Marco reluta, está descrente e não sabe como lidar com Lydia em coma, para Begnino, a vida parece seguir normalmente, ao conversar e fazer planos com Alicia, como se estivesse viva. Em um cotidiano, no mínimo, curioso, Begnino frequenta os locais que Alicia costumava frequentar, conversa e insiste em querer casar-se com a personagem. Um homem ingênuo e, até mesmo, um pouco infantil, parece viver para uma pessoa e um corpo que, por sua vez, parece dali estar bem distante.

O drama atinge o seu clímax quando Marco descobre que Lydia o abandonaria e, então, decide deixar a cidade. E quando Begnino, ao narrar para Lydia um filme que havia assistido, ao que tudo indica, mantém relação sexual com a bailarina em coma. Pouco depois, Alicia, mesmo em coma, fica grávida, e o escândalo se estabelece, culminando na prisão de Begnino e na volta de Marco, para ajudar o amigo. Na prisão, Begnino segue vivendo em nome da bailarina, quando diz ao amigo que a única coisa que lhe interessa é saber de Alicia e do bebê.

Marco descobre, então, que Alicia saiu do coma, algo pouco provável cientificamente, e que o bebê havia morrido. Era um menino. Sem coragem, nada revela ao amigo, que, ao ingerir uma dose tripla de medicamentos, comete o suicídio, esperando, no entanto, entrar em coma e, assim, 'acompanhar Alicia'. Begnino morre. E Marco reencontra Lydia em uma apresentação de ballet, no mesmo local em que Begnino o havia visto chorando, na cena que inicia a obra.

Para Begnino não parece haver morte. Para o médico que assiste a Marco, poucas são as chances de retorno do coma. Entre as enfermeiras, a maioria não acredita na possibilidade de recuperação. Dessa maneira, diferentes são as percepções, inclusive dos profissionais de saúde envolvidos com o cuidado das que experimentam o coma. Para a maioria, é como se as mulheres estivessem mortas, mas, para o enfermeiro Begnino, estão vivas e, a qualquer momento, podem despertar e retornar à vida social.

Coma, prolongamento da vida, corpos inertes, amor, desejo, abuso e assistência médica compõem o desenho dessa obra cinematográfica. Salta-nos aos olhos a dúvida quanto ao que se passa enquanto se vive o coma, o que se sente, se escuta e/ou se entende e, assim, nos deparamos com múltiplos sentidos de vida, mas, sobretudo, de morte.

\section{Morte: sentidos de ontem e de hoje}

Para pensarmos sobre a morte ou muitas leituras sociais do que seria morrer, 'morrer bem' e/ ou 'morrer mal' ao longo de nossa história, o artigo O nascimento do hospital' parece ser um bom e interessante começo. Segundo o autor, antes da modernidade, a morte era percebida como algo corriqueiro, no sentido de que pouco se fazia para evitá-la. E os hospitais eram uma espécie de 'morredouro', para onde as pessoas se dirigiam quando não havia mais esperança. Era igualmente o local de vivência dos 'desviantes', dos loucos, dos andarilhos e dos miseráveis. Nesse sentido, funcionava mais como um asilo ou albergue do que como espaço de cura e de reestabelecimento da ordem. Na mesma linha, a morte era interpretada como uma consequência divina e, por essa razão, 
segundo tal filósofo, a presença de religiosos e de pessoas que praticavam a caridade era bem mais frequente nos hospitais.

Dessa forma, conforme esse mesmo autor, a noção de cura como o que controla e evita a morte, e de hospital como o espaço de prolongamento da vida, parecem ter despontado com o nascimento da medicina moderna. Em defesa da sociedade ${ }^{2}$, o autor ainda conjuga tais mudanças ao que denominou de 'teoria da soberania'. E isso porque, em sua leitura, antes da modernidade, vivíamos sob a ideia de que o soberano 'fazia morrer e deixava viver', detendo o controle sobre a morte dos que compunham a sociedade, mediante castigos e controle social; enquanto, a partir da modernidade e novas práticas de poder, teríamos passado a viver sob o 'deixar morrer e fazer viver', dando ênfase à vida mais longa, ao cuidado da população, de sua saúde e bem-estar em prol de interesses políticos e econômicos. É com essa releitura que o Estado teria passado a atuar no sentido de estender a vida, praticando o que esse autor chamou de 'biopolítica'. Época de 'estatização do biológico', de doença a ser evitada e de saúde a ser cotidianamente construída e vigiada. Para tanto, a medicina moderna, enquanto ciência e prática discursiva, teria sido de fundamental importância, assim como os seus operadores, que, a partir de então, ganharam destaque social e reconhecimento, antes destinado aos clérigos.

Dessa maneira, partindo dessa leitura, pode-se apontar, portanto, para uma repaginação da acepção de morte entre os séculos 16 e 18, junto de algumas outras mudanças, já bem conhecidas, de ordem política, econômica e social, ocorridas com a passagem do medievo para a modernidade. Em certo sentido, a morte também se vê secularizada, ao passar a pertencer ao âmbito da ciência e da gestão humana, reiterando a perspectiva de que a morte pode ser lida de maneiras diferentes ao longo dos tempos e dos espaços.

\section{Boa morte e crítica à biopolítica no fim da existência}

Com essa virada paradigmática, 'viver bem' passa a ser socialmente entendido como ter 'vida longa' e, mais recentemente, 'viver com qualidade'. E, assim, advém o elogio e a crítica, a um só tempo, tanto à tecnologia quanto à farmacologia utilizada no mundo da saúde.

Para explorar essa alteração histórica e cultural da noção de morte, que não consegue ser dissociada da ideia de vida, já que a vida significa a morte por contraposição e vice-versa, recorrer a alguns artigos de uma antropóloga dedicada à saúde ${ }^{3,4}$ e estudiosa dessa temática, parece-me frutífero, instigante e elucidativo. Em um artigo de 2003, 'Tecnologia e morte natural: o morrer na contemporaneidade', a autora salienta que, com o desenvolvimento do 'ventilador artificial' e da acepção de 'morte cerebral', passa a vigorar uma leitura de 'morte moderna', a do morto controlado por máquinas, que tem a vida porque conjugado a uma máquina, quase como um ciborgue.

Essa 'morte moderna' seria, então, a encontrada nos centros e unidades de terapia intensiva (CTIs e UTIs), onde deparamo-nos com pessoas sem escolha, ou quase, à mercê dos cuidados da equipe que compõe o centro e da tecnologia. É lógico que o desenvolvimento da tecnologia é de extrema relevância e importância, trata-se de uma invenção humana que salva vidas e que, muitas vezes, a prolonga em busca de esperança; por isso, não se trata aqui de simplesmente negar a tecnologia, mas de pedir atenção para o outro lado da moeda e que tem despontado com intensidade nos últimos anos.

Esse, ao menos, parece ser o sentido trilhado em seus escritos, que, no limite, tematizam o excesso de tecnologia e o desaparecimento do doente enquanto pessoa. Nessa chave, a morte funciona como sinônimo de fracasso para o médico e para o hospital. Enquanto, na morte 'pós-moderna', mais recentemente tematizada pela autora, interessaria, antes, 'a qualidade de vida' e a 'escolha' daquele que tem a sua existência prolongada mediante tecnologia, tanto em coma como em estados vegetativos.

De acordo com suas linhas, essa outra leitura vem amparada por uma ideia de 'boa morte', que é a morte com qualidade, na qual o moribundo ou a família pode e deve participar das decisões tomadas pela equipe médica e, na qual, morrer é, sobretudo, percebido como uma etapa da vida, e não como uma desgraça a ser evitada. Envolvendo, de saída, portanto, uma crítica à medicalização, à noção de que a juventude é a melhor etapa da existência, e a de que morte significaria, per si, uma fragmentação dos vínculos sociais. Nesse sentido, nesses casos, questiona-se o excesso de tecnologia e valoriza-se o uso das 'tecnologias leves', ou seja, as tidas como 'não invasivas'. 
Segundo a leitura dessa autora, o requerimento contemporâneo pela 'boa morte' estaria conectado ao fato de a geração que ora morre ser a geração dos anos de 1960, a da contracultura, da tentativa de resgate do romantismo e da ideia de totalidade da pessoa perante o racionalismo exacerbado e notadamente moderno. Nesse diapasão, o ideário da 'boa morte' viria, genealogicamente, casado a uma ideia de pessoa e em uma geração específica, cuja relação com o excesso de tecnologia e suposto desencantamento do mundo sempre fora pautada, assim como a demanda pela liberdade, escolha e autonomia.

Se ora recorro a tais estudos ${ }^{4}$, é para problematizar o que se tem discutido por dignidade e autonomia de escolha dos pacientes em coma e em estado vegetativo, quanto aos procedimentos a serem realizados e técnicas de prolongamento da vida. Nessa esteira, não são raras as cenas de 'Fale com Ela' que nos sugerem, quando não escancaram, a possibilidade de despersonalização do paciente e a inexistência da discussão a respeito da ideia de 'boa morte', atualmente valorada no interior de alguns CTIs.

Logo no início do filme, deparamo-nos com a cena em que Alicia menstrua e os enfermeiros não se dão conta de tal fato. Surpresos, logo jogam sabão e a manipulam como se lavassem louça ou fizessem qualquer outra tarefa doméstica. Essa cena traz à baila algo da intimidade feminina, ao menos na leitura do mundo ocidental pautado pelo dimorfismo sexual, e despersonaliza a mulher e o corpo feminino, tomado como objeto de manipulação. E o curioso é que isso se dá também da parte de Begnino, que, na contramão dos demais personagens, costuma reconhecer vida no corpo moribundo.

Lydia morre, não retorna do coma, já Alicia vive quatro anos em coma e, excepcionalmente, retorna à vida. O coma é um estado liminar, o que conjuga vida e morte. Vida no sentido biológico, mas morte no sentido social. Por isso, algumas famílias de pessoas em coma e pacientes, ainda conscientes, têm reivindicado o direito de eutanásia. Nessa esfera, ter de demandar o direito de morrer soa-me como ilustração do pensado quanto à 'biopolítica' e ao investimento estatal no prolongamento da vida ${ }^{4}$, muitas vezes em detrimento dos anseios daquele que vive ou está morto dessa maneira.

Em um texto mais recente, 'Demanda por eutanásia e condição de pessoa: reflexões em torno do estatuto das lágrimas', a mesma autora ${ }^{5}$ discute a crescente demanda no mundo por esse direito de morrer, trazendo à tona o caso de um australiano tetraplégico, antes, praticante de esportes radicais, que, em razão, de 'nem mesmo poder enxugar as suas lágrimas', solicita ao Estado o direito de que o matem. Em países com Holanda, Bélgica e Uruguai, a eutanásia existe enquanto um direito, em que pese cada qual possuir legislação e situações específicas. Na Suíça, desde 1998, existe uma organização, a 'Dignitas', que propicia a eutanásia para aqueles que a desejarem, e tem despertado, segundo essa mesma estudiosa, uma espécie de 'turismo do suicídio', para onde as pessoas têm viajado para conseguir morrer. Enquanto no Brasil, conforme artigo 41 do Código de Ética Médica ${ }^{6}$, a prática da morte antecipada é proibida e configura homicídio, ressalvado, contudo, o dever de se observar o desejo do paciente e de sua família quanto ao destino do tratamento.

Sendo assim, corpo, potência e capacidade de ação figuram, em casos como esses, como cárcere e ausência de vida, sinalizando quão tênue pode ser o limite que separa vida/morte, bem como vida de existência social e autonomia; posto que o que, para alguns, poderia ser prolongamento da vida, para outros, pode ser 'morte em vida', vida que é sofrimento e despersonalização, aproximando-se, por conseguinte, muito mais da morte do que da vida.

Alicia fica grávida e perde a criança, mas não toma conhecimento de nenhum dos fatos. Vive uma relação com Begnino, sem saber tê-la vivido. É manuseada como uma boneca e torna-se um brinquedo do enfermeiro, que, a despeito de amá-la, trata-a conforme os seus anseios e suas próprias expectativas. Tudo sem que tenha a oportunidade de opor-se ou de questionar. Ela representa uma exceção, pois retornou do coma. E os outros pacientes que se veem conectados aos ventiladores artificiais, o que pensar a respeito de sua pessoa, de sua capacidade de escolha? E até onde pode seguir o uso da tecnologia em nome do bios, quando o próprio enfermo não quer mais viver? Esses seriam alguns dos impasses experimentados na contemporaneidade no tocante aos muitos sentidos de morte, em tempos de altíssima tecnologia e de gestão estatal da vida. E, afinal, estão vivos ou estão mortos? 


\section{Nascer e morrer: de perto e de longe}

Se percebemos que morte/vida se veem muito mais imbricadas do que a priori poderíamos aventar a partir de uma leitura dicotômica de mundo, e que, ambas, estão muito além do pulsar biológico, ao refletir sobre 'Fale com ela', creio que entre o morrer e o nascer existem muitos pontos de semelhança. Nesse sentido, a antropologia do parto/do nascimento, campo no qual me situo especificamente, se vê, por um lado, interpelada e, por outro, também como mobilizadora da antropologia da morte.

Segundo a autora já mencionada ${ }^{4}$, a ideia de 'boa morte' aparece também como 'morte natural' ou como 'morte mais natural possível' - marca também presente na filosofia do parto humanizado ou do 'parto natural' dos dias atuais, ou seja, aquele que acontece com o mínimo de intervenção possível e na contramão da cesárea, e que constitui o objeto de meus principais interesses de pesquisa há anos. Em 1991, surge, na Inglaterra, o 'Centro de Morte Natural', onde há o preparo para a morte mediante exercícios corporais e redução da ansiedade, assim como também acontece nos grupos de preparo para o parto em que realizei minha etnografia. E, nesse sentido, a premissa do 'nascer sorrindo' parece poder ser estendida ao 'morrer sorrindo'. Em outro sentido, de maneira bem próxima, entre os adeptos da "boa morte", aparecem também relatos de êxtase ao morrer", como entre algumas mulheres adeptas do parto humanizado têm narrado nos anos mais recentes na experiência brasileira ${ }^{8}$. Existe a proposta do leito compartilhado, como no nascimento mais natural, entre o paciente e alguém da família; bem como aparecem relatos de massagens, fitas audiovisuais e uso de florais para, segundo a autora, 'ir ao encontro da luz'7. Essa proximidade discursiva entre os modos de morrer, estudados pela autora aqui citada, e os modos de viver, que tenho investigado, parece ainda mais marcada quando nos deparamos com a existência de 'a parteira para o outro mundo', ou seja, da parteira que auxilia na morte, assim como a que aparece nas cenas de parto.

Por essa razão, a autora avalia essa postura da 'boa morte' como um retorno pagão à natureza, presente tanto nos discursos orientados ao nascer quanto ao morrer, como já pontuou uma outra antropóloga em sua tese de doutorado sobre o parto humanizado ${ }^{9}$. Nesses espaços sociais, a tecnologia pode ser vista como antagonista da 'boa morte', também apreendida como morte natural, como também aparece no ideário da humanização do parto e do nascimento.

Isto posto, parece fazer sentido que a autora em questão perceba uma relação entre aqueles que defendem tal filosofia e a geração de 1960, porque essa geração, segundo os seus escritos, foi - e nesse ponto, penso eu -, também, a precursora da filosofia do parto natural/sem dor, a do movimento hippie e dos direitos civis, sendo também a dos slogans 'o meu corpo me pertence' ou 'o pessoal é político'. A 'boa morte', nesses casos, é a morte natural igualmente construída, tecida a partir da individualidade ${ }^{10,11}$ e do 'cuidado de si', revelando-nos mais um modelo social de morte, aquele que não a pensa como surpresa e inevitabilidade e, tampouco, como prolongamento artificial e simples manutenção do bios, mas como uma morte criada mediante o preparo e o protagonismo.

De tudo, o que me parece restar é a pluralidade de leituras possíveis a respeito de morte, de vida e de suspensão da vida. É no jogo entre opostos e em leituras que os aproximam e os distanciam que podemos nos dar conta dessa multiplicidade. Procurei, nessa ocasião, realizar um recorte e explorar o campo da assistência médica, o interesse estatal e as tecnologias de prolongamento da vida, de um lado, e, de outro, as leituras interpretativas realizadas por aqueles que experimentam tais situações ou buscam evitá-las, 'preparando-se para morrer'. 'Fale com Ela', por tudo isso, é sem dúvida uma abertura para uma gama de interpretações, como o é o cinema em geral e enquanto linguagem que conjuga palavras e sentimentos... 


\section{Referências}

1. Fale com ela. Hable con ella. Direção: Pedro Almodóvar. Espanha; 2002. 112 min.

2. Foucault M. Microfísica do poder. Rio de Janeiro: Graal; 1993.

3. Foucault M. Em defesa da sociedade. São Paulo: Martins Fontes; 2002.

4. Menezes RA. A medicalização da esperança: reflexões em torno da vida, saúde/doença e morte. Amazon Rev Antropol. 2013; 5(2):478-98.

5. Menezes RA. Demanda por eutanásia e condição de pessoa: reflexões em torno do estatuto das lágrimas. Sex Salud Soc. 2011; 9: 37-53.

6. Conselho Federal de Medicina. Código de Ética Médica. Resolução 1931/2009. Aprova o Código de Ética Médica. Diário Oficial da União. 24 Set 2009. Seção 1:90.

7. Menezes RA. Tecnologia e morte natural: o morrer na contemporaneidade. Physis. 2003; 13(2):129-47.

8. Carneiro RG. Cenas de parto e políticas do corpo: etnografia de experiências femininas de parto humanizado [tese]. Campinas (SP): Instituto de Filosofia e Ciências Humanas da Universidade Estadual de Campinas; 2011.

9. Tornquist CS. Parto e poder: o movimento de humanização do parto no Brasil [tese]. Florianópolis (SC): Programa de Pós-Graduação em Antropologia Social, Universidade Federal de Santa Catarina; 2004.

10. Salem T. O casal grávido: disposições e dilemas da parceria igualitária. Rio de Janeiro: Editora FGV; 2007.

11. Velho G. Observando o familiar. In: Nunes EO, organizador. A aventura sociológica. Rio de Janeiro: Zahar; 1978. p. 36-46. 
Este artigo pretende refletir sobre as múltiplas acepções de morte na contemporaneidade, a partir da obra cinematográfica 'Fale com ela', de Pedro Almodóvar. Para tanto, dialoga com o filme e com a leitura socioantropológica de Menezes sobre 'boa morte', 'morte moderna' e 'morte pós-moderna', tomando as considerações sobre a noção de pessoa e de naturalidade. Esse esforço termina por resultar, ao final, em outra aproximação entre o morrer, o viver e o nascer nos dias atuais, pensando em suas aproximações e semânticas na atualidade

Palavras-chave: 'Fale com ela'. Morte. Vida. Pessoa.

\section{Life on hold: 'Talk to her' and the meanings of death}

This paper aims to reflect on the multiple meanings of death in today's society, starting from the film 'Talk to her', by Pedro Almodóvar. For this, the film and the socioanthropological reading of Menezes on 'good death', 'modern death' and 'postmodern death' are discussed, taking into consideration notions about people and naturalness. This effort ultimately ends up resulting in another approach between death, life and birth within current days while thinking about their approaches and semantics today.

Keywords: 'Talk to her'. Death. Life. Person.

\section{La vida en suspensión: 'Habla con ella' y los sentidos de la muerte}

El objetivo de este artículo es reflexionar sobre las múltiples acepciones de muerte en la contemporaneidad, a partir de la obra cinematográfica 'Habla con ella' de Pedro Almodóvar. Para ello, dialoga con la película y con la lectura socio-antropológica de Menezes sobre la 'buena muerte', la 'muerte moderna' y la 'muerte post-moderna', tomando sus consideraciones sobre la noción de persona y de naturalidad. Ese esfuerzo acaba finalmente resultando en otras aproximación entre el morir, el vivir y el nacer en los días actuales, pensando en sus aproximaciones y semánticas en la actualidad.

Palabras clave: 'Habla con ella'. Muerte. Vida. Persona. 
